2008-01-01

\title{
Reduction of Ground-Plane-Dependent Effects on Microstrip-Fed Printed Rectangular Monopoles
}

\author{
Matthias John \\ Technological University Dublin, matthias.john@tudublin.ie \\ Jonathan Evans \\ Technological University Dublin \\ Max Ammann \\ Technological University Dublin, max.ammann@tudublin.ie
}

See next page for additional authors

Follow this and additional works at: https://arrow.tudublin.ie/engscheceart

Part of the Electrical and Computer Engineering Commons

\section{Recommended Citation \\ John, M. et al. (2008) Reduction of Ground-Plane-Dependent Effects on Microstrip-Fed Printed Rectangular Monopoles. IET Microwaves, Antennas \& Propagation, February, 2008, Vol.2, pp.42-47. doi:10.1049/iet-map:20070053}

This Article is brought to you for free and open access by the School of Electrical and Electronic Engineering at ARROW@TU Dublin. It has been accepted for inclusion in Articles by an authorized administrator of ARROW@TU Dublin. For more information, please contact arrow.admin@tudublin.ie, aisling.coyne@tudublin.ie, gerard.connolly@tudublin.ie.

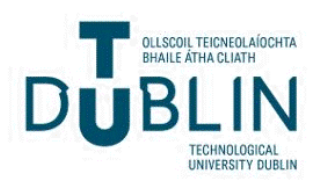


Authors

Matthias John, Jonathan Evans, Max Ammann, J. C. Modro, and Z. N. Chen

This article is available at ARROW@TU Dublin: https://arrow.tudublin.ie/engscheceart/34 


\title{
Reduction of ground-plane-dependent effects on microstrip-fed printed rectangular monopoles
}

\author{
M. John, J.A. Evans, M.J. Ammann, J.C. Modro and Z.N. Chen
}

\begin{abstract}
Methods to mitigate the strong dependence of impedance bandwidth on the groundplane size for a rectangular printed planar monopole is described. It is shown that the bandwidth limitation may be overcome by introducing feed-line asymmetry, which alters the purity and the $Q$ of the higher frequency modes and by ground-plane augmentation, which effects the lower frequency modes. A method of extending the ground plane without increasing the overall antenna size is shown to improve both the bandwidth and gain and also to enable the use of significantly smaller ground planes. The effects of these techniques on radiation pattern are discussed.
\end{abstract}

\section{Introduction}

The planar monopole antenna has received much attention in the last decade or so because of its wide impedance bandwidth $[1,2]$ and many techniques have been examined to enhance performance, including the use of feed-line asymmetry [3, 4] and fractals [5]. However, the classical orientation of the radiator with respect to the ground plane has placed limitations on its practical use, particularly in portable and fixed terminal devices. The recent introduction of a ground plane printed on the opposite side of a substrate $[6,7]$ has given these monopoles a lower profile, making them more suitable for integration. The rectangular printed element with microstrip feed has been optimised for wide bandwidth [7] and the use of EBG surfaces have been used as a reflector to provide directivity with a low profile [8]. Printed circular disc monopoles have recently been shown to be a good candidate for ultra-wideband (UWB) systems [9]. A dual-feed mechanism has been proposed for rectangular shapes, which improves polarisation purity, while maintaining very wide bandwidth [10]. It is well known that monopole-type antenna performance is dependent on ground-plane effects [11] and an evaluation of the dependence of printed strip monopole performance on ground-plane size has been carried out [12]. The shaped ground plane has recently been investigated for increased impedance and pattern bandwidth [13]. A stepped co-planar waveguide (CPW) feed-line impedance technique to improve matching for UWB has also been reported [14]. Much of the literature has concentrated on optimisation of impedance bandwidth for these elements and very little has been reported on overcoming the

\footnotetext{
(C) The Institution of Engineering and Technology 2008 doi:10.1049/iet-map:20070053

Paper first received 11th May 2006 and in revised form 14th August 2007 M. John, J.A. Evans and M.J. Ammann are with Centre for Telecommunications Value-chain Research, School of Electronic and Communications Engineering, Dublin Institute of Technology, Kevin Street, Dublin 8, Ireland

J.C. Modro is with TDK Electronics Ireland Ltd., European Technical Centre, CityWest, Co Dublin, Ireland

Z.N. Chen is with Institute for Infocomm Research, 20 Science Park Road, \#0234/37 TeleTech Park, Singapore 117674, Singapore

E-mail: max.ammann@dit.ie
}

limitations imposed on the lower frequencies and impedance bandwidth when the ground plane is very small.

In this paper, the relationship between impedance bandwidth and ground-plane size is examined along with how the introduction of feed-line asymmetry can mitigate the limitation imposed by a small ground plane. The use of a windowed ground plane [15], which does not increase overall antenna size, is also examined in relation to reducing ground plane-dependent effects. This technique is similar to a wide-slot antenna but with a large planar-monopole microstrip feed. The bandwidth of wide-slot antennas have been enhanced using a microstrip fork-like feeds $[16,17]$. More recently, a U-shaped tuning stub with tapered feed line has been proposed as an optimised feed structure for elliptical and circular UWB slot antennas, using both the microstrip and CPW feeds [18]. A compact fractal-based slot fed by a fork-like element with band notching has been recently reported [19].

The techniques proposed in this paper are useful for printed antennas operating from 1.6 to $8 \mathrm{GHz}$. This band covers many systems such as WLAN (IEEE 802.11a, b, g, j) and WiMAX $(2.3-2.4,2.5-2.7$ and $3.6-3.8 \mathrm{GHz})$. The recent EU (until 2011) allocated UWB spectrum from 4.2 to $4.8 \mathrm{GHz}$ as well as the US first generation multiband-UWB systems which operate in the group A band of frequencies $(3.1-4.9 \mathrm{GHz})$ are also included. The antenna also covers the spectrum allocated to group $\mathrm{B}$ (4.9-6.0 GHz) and group $\mathrm{C}(6.0-8.1 \mathrm{GHz}) \mathrm{UWB}$ devices. This would be appropriate for the convergence of technologies in applications like tablet PCs.

\section{Antenna geometry}

The antenna is printed on one side of an FR4 substrate with the ground plane on the other side. The monopole plate is rectangular, with the dimensions $w_{\mathrm{p}}=20 \mathrm{~mm}$ and $h_{\mathrm{p}}=30 \mathrm{~mm}$, which is fed by a microstrip feed line of width $w_{\mathrm{f}}=2.5 \mathrm{~mm}$ via an SMA microstrip-launch connector. The optimum feed gap between the plate and the ground plane is $h_{\text {gap }}=2 \mathrm{~mm}$ [7]. This gives the largest impedance bandwidth because the various modes undergo little impedance variation with frequency, because of a balance between the feed-probe inductance and plate-to-ground-plane capacitance. The feed gap has little effect on the lower edge frequency (LEF). The FR4 properties are: copper cladding: $1 \mathrm{oz} / \mathrm{sq} \mathrm{ft}$, EDC, loss 


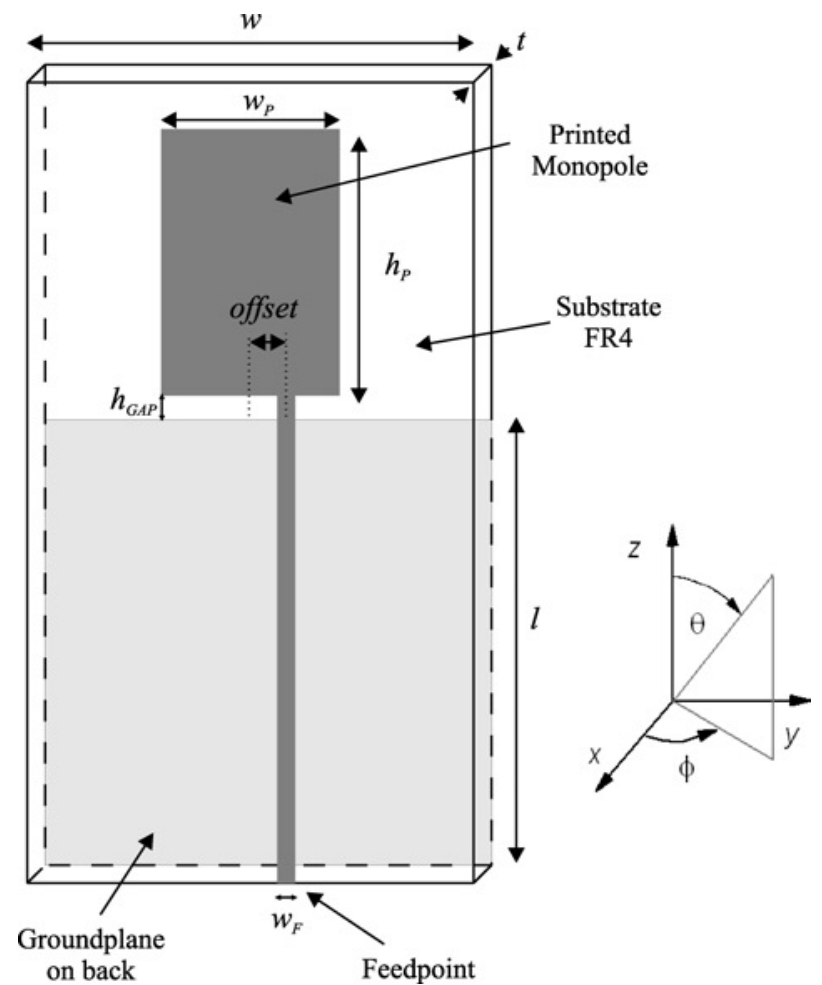

Fig. 1 Geometry of the printed plate monopole, showing asymmetrical feed arrangement and co-ordinate system $\left(w_{p}=20 \mathrm{~mm}\right.$, $h_{p}=30 \mathrm{~mm}, h_{\text {gap }}=2 \mathrm{~mm}$ and $G P=l \times w$ which is varied from $20 \times 20 \mathrm{~mm}$ to $80 \times 80 \mathrm{~mm}$ )

tangent $\delta=0.02$, dielectric constant $\varepsilon_{\mathrm{r}}=4.3$ and substrate thickness, $t=1.52 \mathrm{~mm}$. The ground plane is square with the dimension $l$, which is varied from $20 \mathrm{~mm}$ $(\mathrm{GP}=20 \mathrm{~mm})$ to $80 \mathrm{~mm}(\mathrm{GP}=80 \mathrm{~mm})$. These are practical sizes for portable and fixed wireless communication terminals. The structure of the antenna and coordinate system is shown in Fig. 1.

\section{Impedance bandwidth}

The antenna was simulated using a CST Microwave Studio, which employs the finite-integration time-domain technique. The source was modelled using a wave-guide port. Fig. 2 shows a plot of simulated and measured return losses for the symmetrically fed plate on a $50 \mathrm{~mm}$ ground plane, which are in good agreement. The measured return

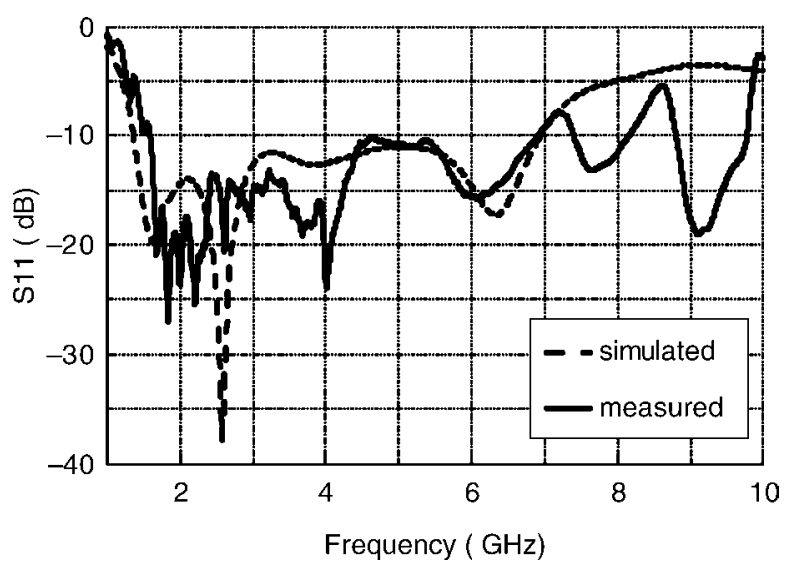

Fig. 2 Plot of measured and simulated return loss for the ground plane optimised $(G P=50 \times 50 \mathrm{~mm})$ printed antenna

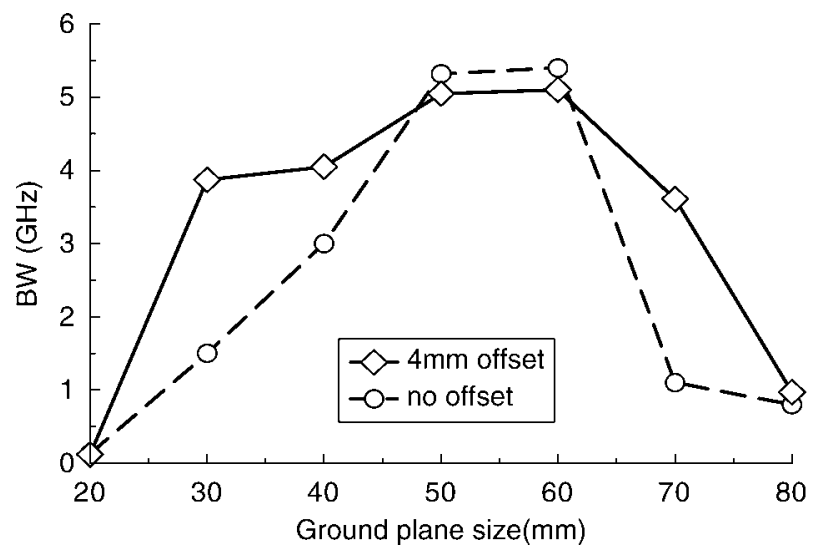

Fig. 3 Plot of measured bandwidth sensitivity to ground-plane size $(20 \times 20 \mathrm{~mm}$ to $80 \times 80 \mathrm{~mm})$ for symmetrically and asymmetrically fed (4 $\mathrm{mm}$ offset) antenna

loss is greater than $10 \mathrm{~dB}$ from 1.57 to $6.91 \mathrm{GHz}$ compared with 1.41 to $6.94 \mathrm{GHz}$ for the simulation.

\subsection{Ground-plane size}

A plot of measured $10 \mathrm{~dB}$ return loss bandwidth for the first resonance is shown in Fig. 3, with the feed line connected to the centre of the plate (symmetrical feed) and the GP size is varied over a range of ground-plane sizes in $10 \mathrm{~mm}$ steps from 20 to $80 \mathrm{~mm}$. It can be seen that the maximum bandwidth occurs when the ground-plane size is in the $50-$ $60 \mathrm{~mm}$ region, where the measured return loss is greater than $10 \mathrm{~dB}$ from 1.57 to $6.91 \mathrm{GHz}$. In this case, the groundplane size is optimised for maximum impedance bandwidth and no further improvement could be gained by introducing feed-line asymmetry, as described below.

\subsection{Feed-line asymmetry}

In many practical design circumstances, the antenna designer may not have the freedom to adjust the groundplane size. In this case, it is shown that an asymmetrical feed line can provide significant bandwidth improvement. This technique has been reported for the 3D classical planar monopole [4], but not investigated for the 2D printed case. An offset in the feed-line symmetry is introduced and a plot of simulated impedance bandwidth (10 dB RL) against offset distance for ground-plane sizes from $20 \times 20$ to $80 \times 80 \mathrm{~mm}$ is shown in Fig. 4. This

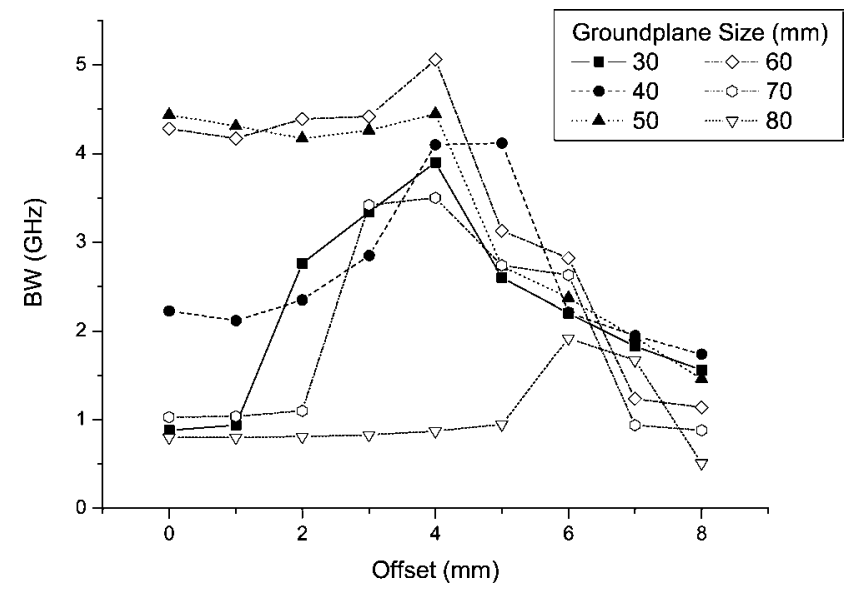

Fig. 4 Plot of simulated impedance bandwidth (10 dB RL) for various GP sizes against offset distance 


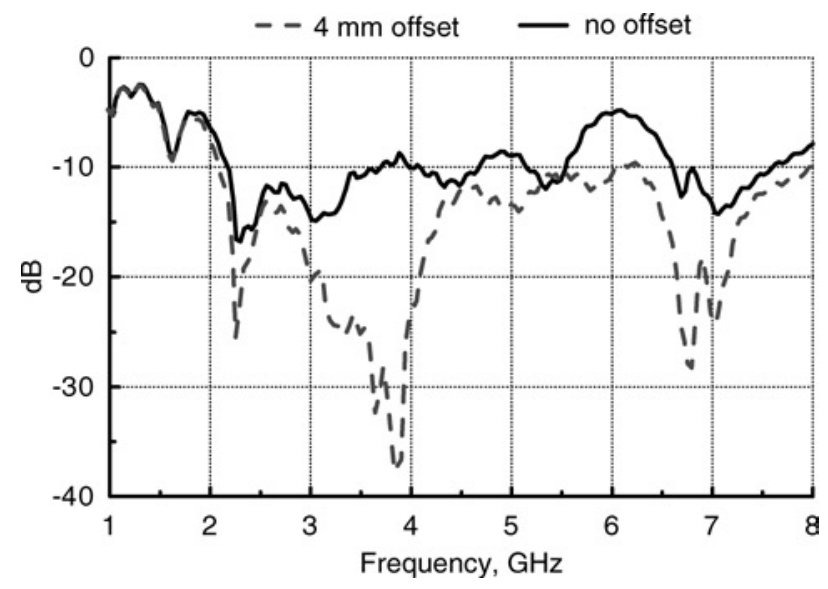

Fig. 5 Plot of measured return loss for the centre fed and offset-fed arrangements with $G P=30 \times 30 \mathrm{~mm}$

shows that the offset feed can improve the impedance bandwidth significantly for non-optimised ground-plane sizes. The distance of $4 \mathrm{~mm}$ is seen to be optimum for the $30 \mathrm{~mm}$ ground plane. In particular, the impedance bandwidth is increased from 1.571 to $3.87 \mathrm{GHz}$ (by $258 \%$ ) for $\mathrm{GP}=30 \mathrm{~mm}$. The measured return loss for $\mathrm{GP}=30 \mathrm{~mm}$ with and without an offset is shown in Fig. 5 where the increase in bandwidth is evident. Plots of the measured real and imaginary components of the input impedance are shown in Fig. 6. When the $Q$ factors of the resonances between the centre-fed and the offset-fed antennas on the $30-\mathrm{mm}$ ground plane are compared, it can be seen that the effect of the offset feed is to broaden the resonances, to reduce their peak resistance and to load their centre frequencies down slightly. It seems that the effect of the offset feed is to reduce the purity (and hence the $Q$ and stored energy)
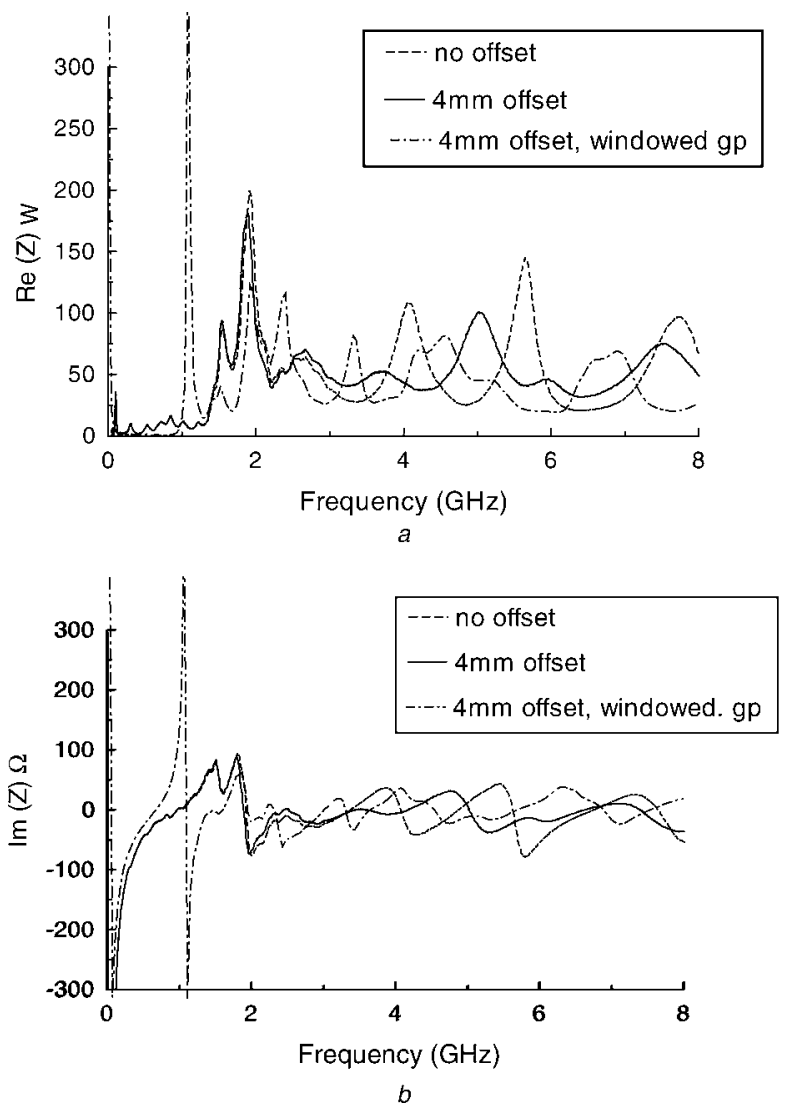

Fig. 6 Plot of the measured Re [Z] and Im [Z] against frequency

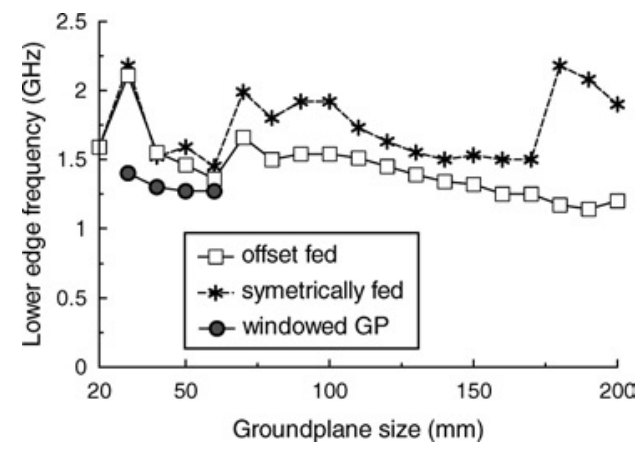

Fig. 7 Variation in the measured LEF (10 dB RL) against ground-plane size $(20 \times 20-200 \times 200 \mathrm{~mm})$

of the higher order modes, especially those dominated by feed-line resonance, compared with the purer centre-feed arrangement. The result is that the impedance is closer to $50 \Omega$ over a wider bandwidth.

\subsection{Lower edge frequency}

It is also noted from Fig. 3, that the feed arrangement introduces no improvement for GP $=20 \mathrm{~mm}$; the bandwidth of the first resonance is only $120 \mathrm{MHz}$ for both feed arrangements. This is due to the absence of a $1.5 \mathrm{GHz}$ ground-plane resonant mode for which the return loss does not reach $10 \mathrm{~dB}$. This can be seen more clearly by observing the variation of LEF with ground-plane size. A noticeable variation in the measured LEF of the $10 \mathrm{~dB}$ return loss impedance bandwidth was observed with a change of GP size. A general decrease in the LEF with frequency can be seen from Fig. 7. However, the plot portrays peaks and troughs, which can be exploited, for small GP sizes. The lowest LEF (for GP $<100 \mathrm{~mm}$ ), was found to be $1.22 \mathrm{GHz}$ for the offset-fed case corresponding to $\mathrm{GP}=65 \mathrm{~mm}$ and $1.39 \mathrm{GHz}$ for the centre-fed case, corresponding to GP $=55 \mathrm{~mm}$. These values have implications for antenna miniaturisation. In contrast, the highest LEF is 2.19 and $2.11 \mathrm{GHz}$ for the symmetrically fed and offset fed, respectively, which occurs at $\mathrm{GP}=30 \mathrm{~mm}$ for both

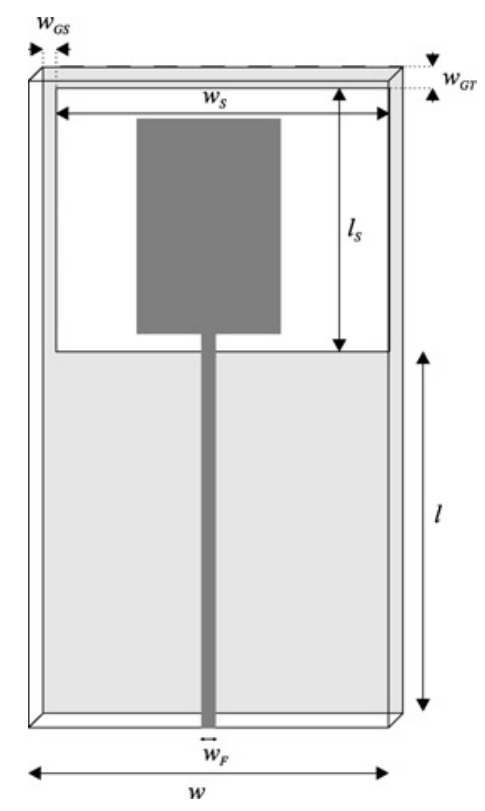

Fig. 8 Geometry of the windowed ground plane $\left(w_{\mathrm{gs}}=0.2 \mathrm{~mm}\right.$, $w_{g t}=2 \mathrm{~mm}, w_{s}=29.6 \mathrm{~mm}, l_{s}=38 \mathrm{~mm}$ )

IET Microw. Antennas Propag., Vol. 2, No. 1, February 2008 
feed arrangements. The degree of excitation of these modes is dependent on the ground plane.

\section{Augmented ground plane}

As shown in Fig. 7, the LEF is significantly increased for the small GP $=30 \mathrm{~mm}$. Since the antenna now operates at a higher frequency, this effectively makes it larger in terms of wavelength and less desirable. In order to reduce the antenna's relative size, the ground plane can be enlarged by making it surround the planar radiator, with the radiator effectively in a ground-plane window as shown in Fig. 8, where the overall substrate size remains the same. This is similar to a wide-slot antenna. However, most wide-slot antennas are fed by CPW or microstrip, using single or forklike feeds. A small triangular and square-shaped feed has been recently reported to excite a wide-slot antenna [20], but these geometries use symmetry, are small compared with the slot dimension and have an overall larger antenna dimension than the antenna proposed here. The dimensions of the windowed ground plane are: $w g s=0.2 \mathrm{~mm}$ and $\mathrm{wgt}=2 \mathrm{~mm}$. The radiating plate is effectively embedded in the ground plane, but on the opposite side of the substrate. The effect of this is to increase the return loss for the lower mode, which more or less disappears because the $\mathrm{GP}=30 \mathrm{~mm}$ in size. Fig. 9 shows the measured return loss plots for the GP $=30 \mathrm{~mm}$ antenna with and without augmented ground plane for both the centre-fed and offset-fed feeds. It can be seen that the lower mode returns for the centre-fed case and has a return loss greater than $10 \mathrm{~dB}$ for $1.36-1.59 \mathrm{GHz}$. When the augmented ground plane is combined with the offset feed, it is clearly seen that $10 \mathrm{~dB}$ return loss bandwidth of the first resonance is $1.36-1.62 \mathrm{GHz}$. For the latter case, the return loss is greater than $7 \mathrm{~dB}$ over the range of $1.31-8 \mathrm{GHz}$. The effect of the windowed ground plane on the input impedance is to reduce the variation of both the real and imaginary components, particularly near the $2 \mathrm{GHz}$ region. This is shown to reduce the LEF from 2.1 to $1.35 \mathrm{GHz}$ for the asymmetrically fed antenna for GP $=30 \mathrm{~mm}$ and this is shown in Fig. 7. It can be seen from Fig. 7, that the windowed ground plane can be used successfully to bring back the lower order modes, which are diminished because of small ground-plane size. This effect is less significant as the ground-plane size increases. For comparison, a UWB antenna was scaled to the same substrate size $(30 \times 70 \mathrm{~mm})$ and with the same ground-plane size $(\mathrm{GP}=30 \times 30 \mathrm{~mm})$. It was found that the scaled UWB

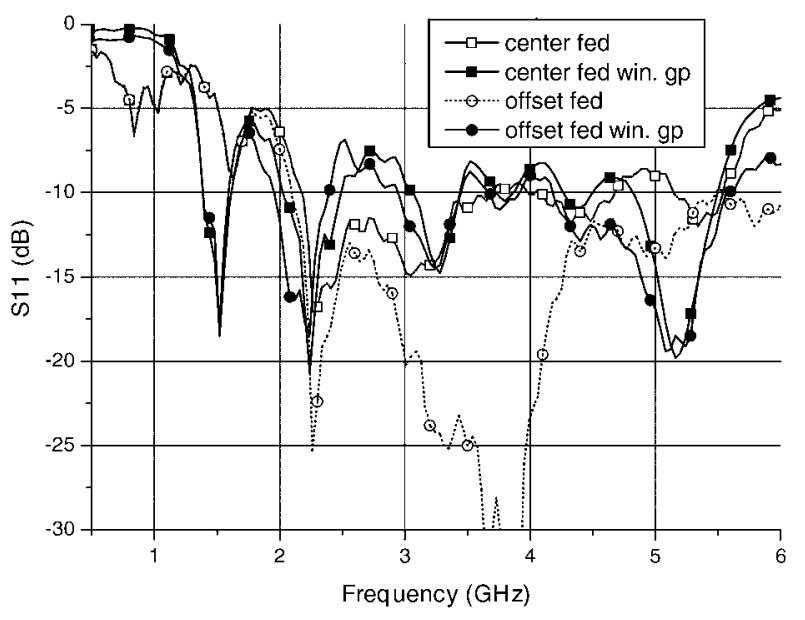

Fig. 9 Plot of measured return loss for the windowed monopole with and without asymmetry in the feed $(G P=30 \mathrm{~mm})$ antenna had a LEF (10 dB RL) of $1.52 \mathrm{GHz}$ compared with $1.36 \mathrm{GHz}$ for a centre-fed windowed antenna, thus a reduction in the LEF for the windowed antenna.

\section{Radiation characteristics}

Simulated plots of surface current indicated that more current is concentrated in the monopole for the offset-fed case than for the centre-fed model, which strongly suggests that more of the power is being accepted by the antenna in the offset-fed case. This is for a mid-range resonance, but it is the one that is most significantly changed by moving the feed position. The ground-plane 'plate' modes do not seem to be strong compared with the antenna-element modes for mid-range resonances, but the top edge of the ground plane is clearly critical to the resonant modes.

A plot of the simulated radiation efficiency and gain against frequency is shown in Fig. 10. It is seen that the use of windowed ground plane improves the gain slightly and also yields greater radiation efficiency, notably at higher frequencies. A greater radiation efficiency is also noted for the offset-fed antenna compared with the centre-fed element, particularly at higher frequencies.

The radiation patterns were measured at 2.45 and $5.2 \mathrm{GHz}$ for $\mathrm{GP}=30 \mathrm{~mm}$, with both the centre-fed and asymmetrical feed arrangements. The measured gain was found to be $2.5 \mathrm{dBi}$ for both feeds at $2.45 \mathrm{GHz}$ and 3.8 and $4.1 \mathrm{dBi}$ for the centre-fed and offset-fed arrangements at $5.2 \mathrm{GHz}$, respectively. The radiation patterns are illustrated in Figs. 11-14. The main effect of the offset-fed monopole is seen to be a reduction of the depth of the
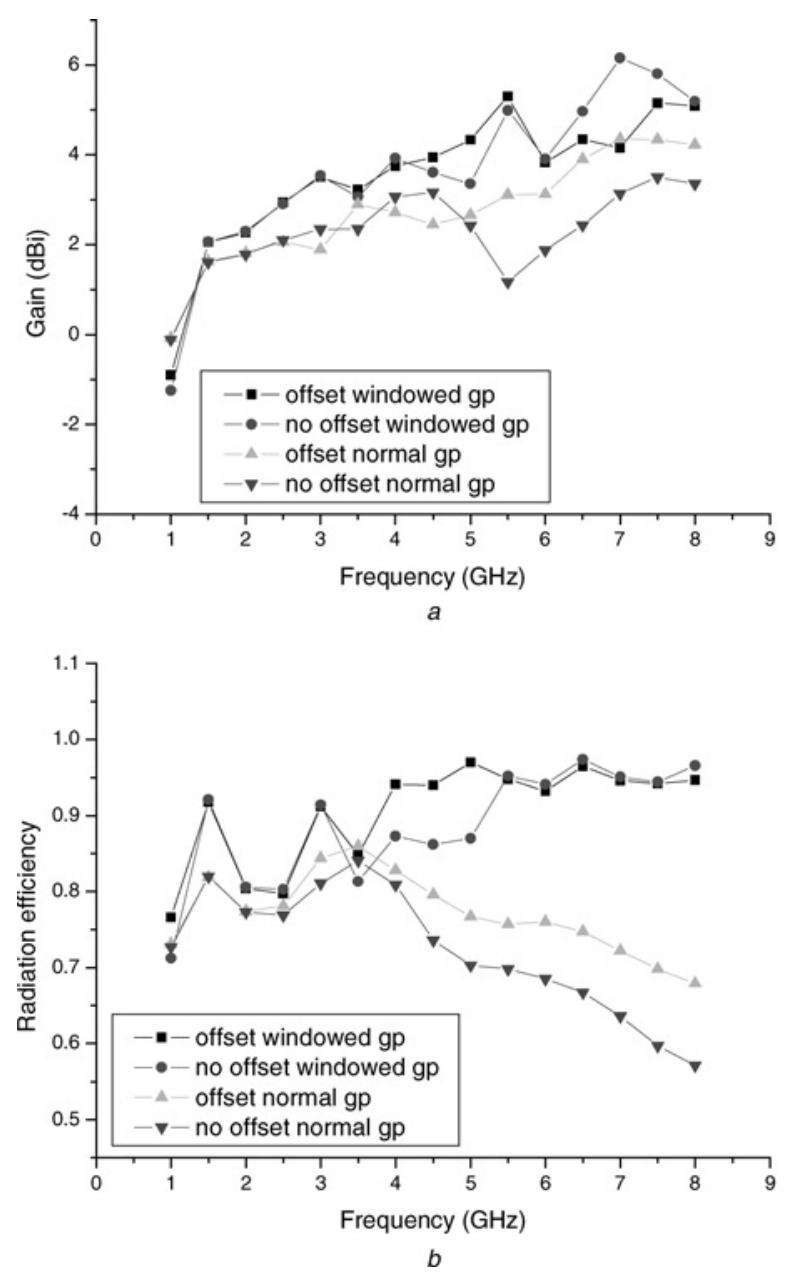

Fig. 10 Plot of simulated radiation efficiency and gain against frequency 

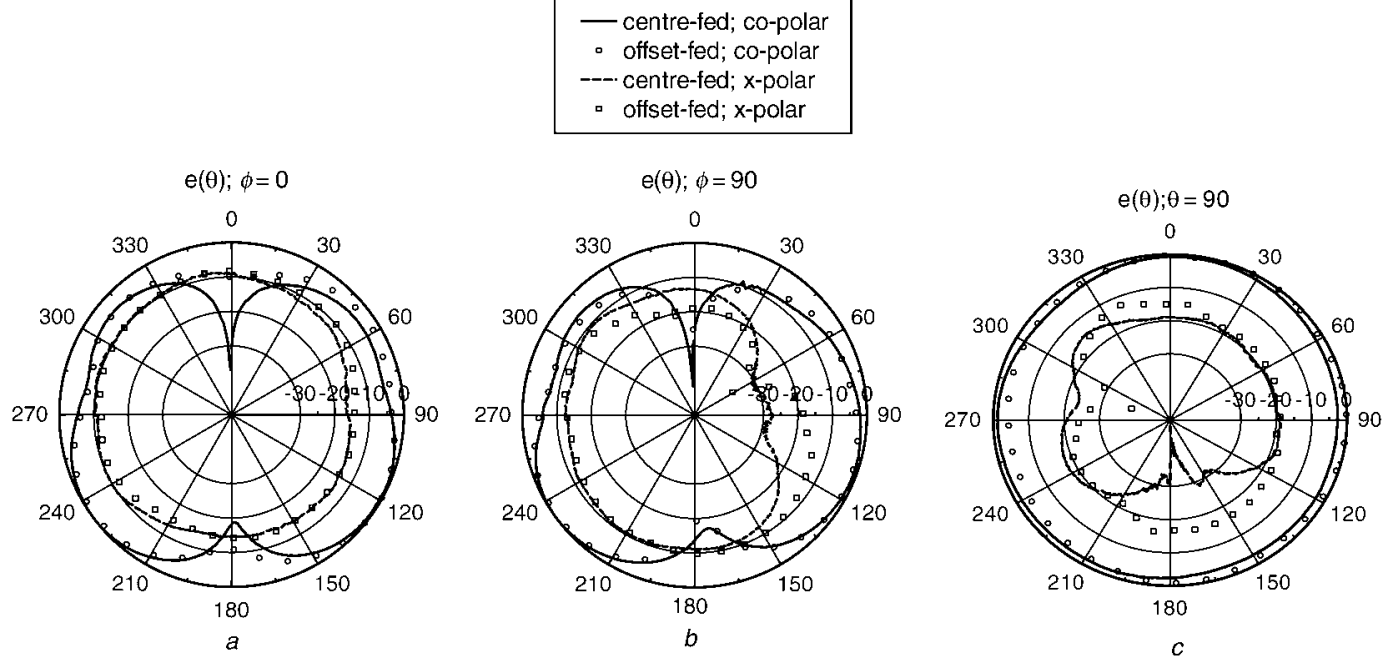

Fig. 11 Measured radiation patterns for the centre-fed and asymmetrically fed antenna for $\mathrm{GP}=30 \mathrm{~mm}(2.45 \mathrm{GHz})$
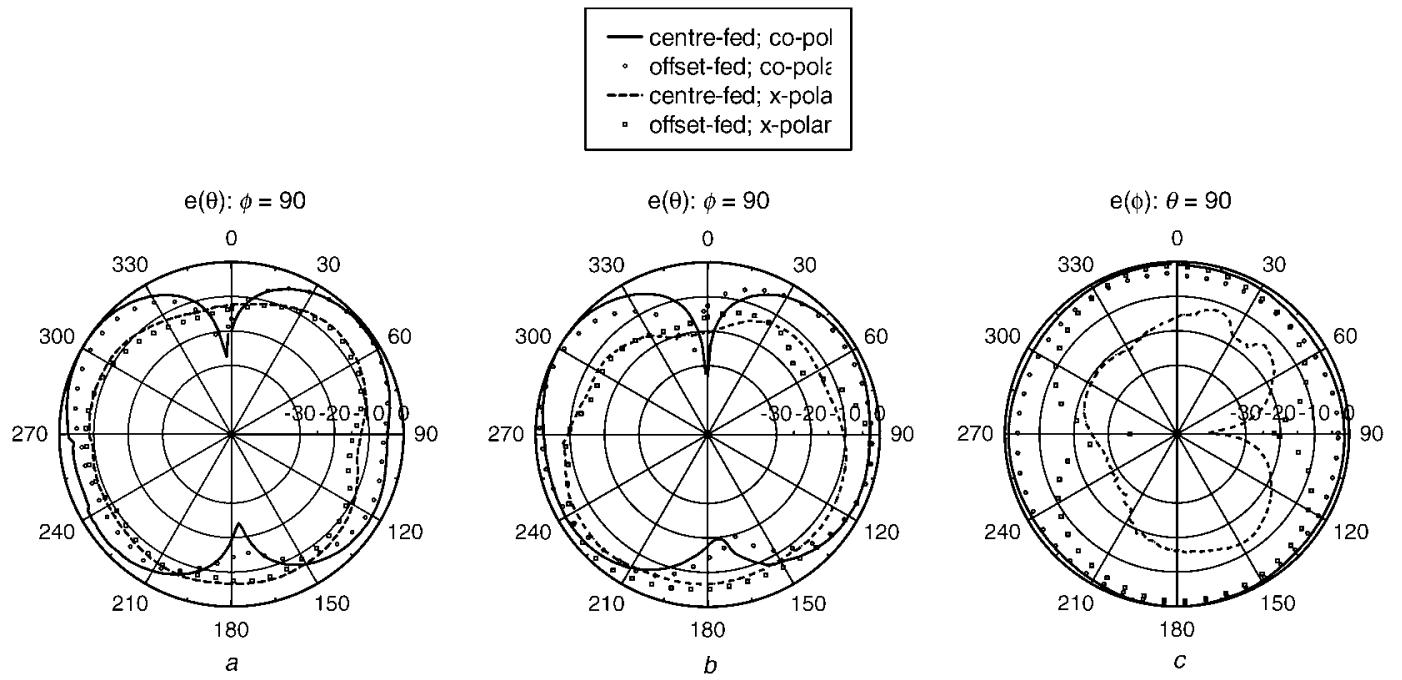

Fig. 12 Measured radiation patterns for the centre-fed and asymmetrically fed antenna with the windowed ground plane for GP=30 $\mathrm{mm}$ $(2.45 \mathrm{GHz})$

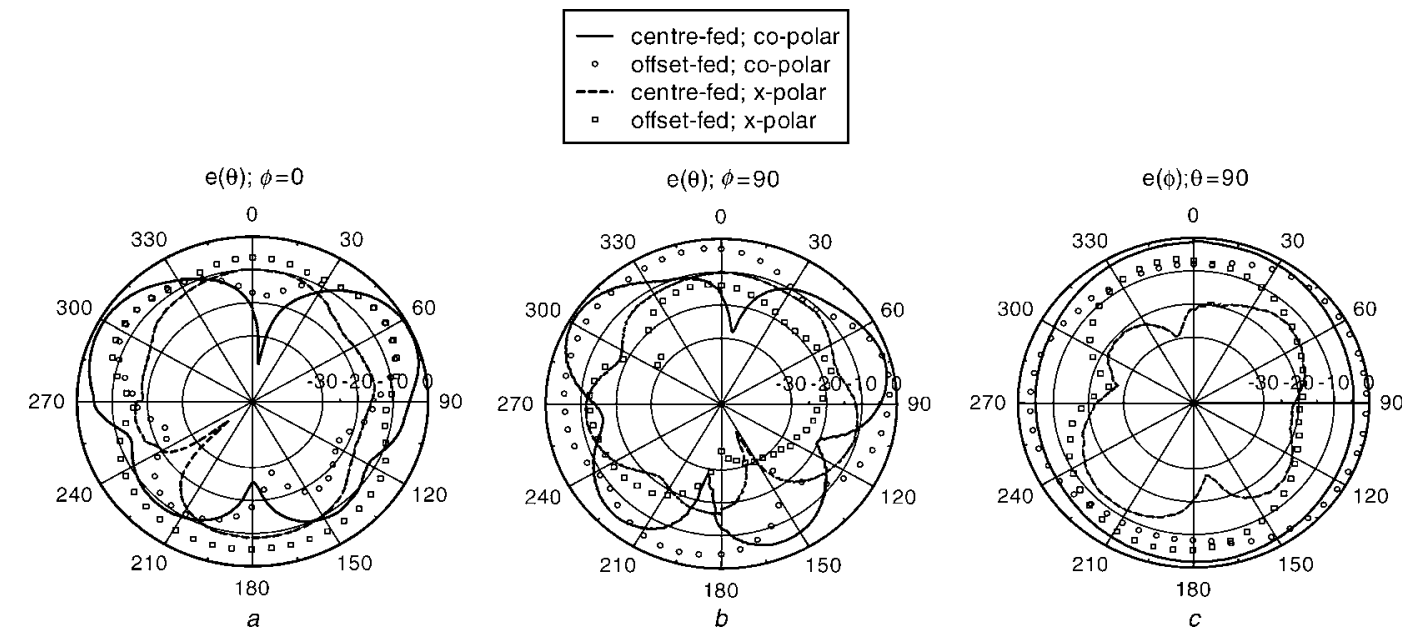

Fig. 13 Measured radiation patterns for the centre-fed and asymmetrically fed antenna for GP=30 mm (5.2 GHz) 

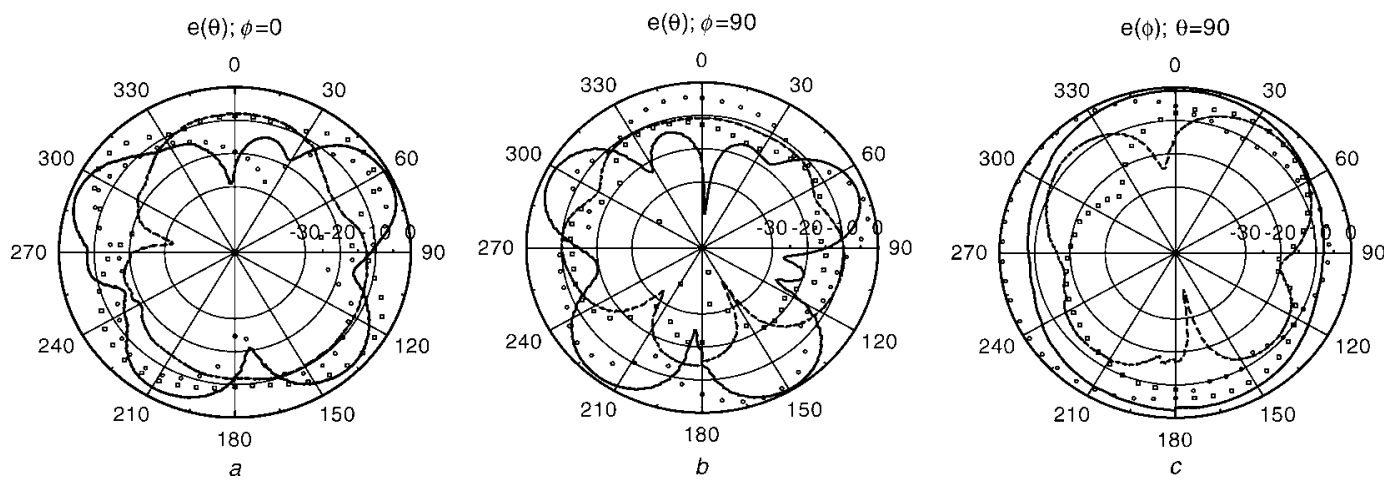

Fig. 14 Measured radiation patterns for the centre-fed and asymmetrically fed antenna with the windowed ground plane for GP=30 mm $(5.2 \mathrm{GHz})$

E-plane nulls for the $\phi=0^{\circ}$ and $90^{\circ}$ cuts, thus improving the omni-directionality of the antenna in this plane. The effect of extending the ground plane on the patterns at $2.45 \mathrm{GHz}$ was found to be minimal for the co-polar plots, except for the null at $\theta=0^{\circ}$ which is reduced by $\sim 10 \mathrm{~dB}$ for the extended ground plane and is shown in Fig. 11. The extended ground plane was found to enhance radiation in the upper hemisphere (region from $\theta=270^{\circ}$ to $90^{\circ}$ for all $\phi$ ) for the lower frequencies. Degradation in the cross-polar performance was evident for both ground-plane types. However, some degradation was seen in the H-plane because of the asymmetry at the higher frequency of $5.2 \mathrm{GHz}$, where a dip of $8 \mathrm{~dB}$ in the pattern is observed as shown in Fig. 13c. The addition of the windowed GP produces a further degradation in the H-plane pattern by $2 \mathrm{~dB}$ as seen in Fig. 14c.

\section{Conclusions}

It is shown that in cases where the bandwidth of printed planar monopoles is limited because of restricted groundplane size, the feed-line asymmetry can significantly increase the bandwidth. For smaller ground planes, the antenna bandwidth is unattractive unless feed-line asymmetry is used. The effect of feed-line asymmetry on radiation pattern is to reduce null depth of the E-plane nulls, improving omnidirectionality. In the case where lower order modes disappear because of small ground-plane size, a windowed groundplane technique is shown to mitigate this effect, without increasing the overall antenna size or degrading the radiation pattern. This type of design is suited to applications such as tablet PCs where convergence of radio standards is served by a single antenna behind the screen.

\section{References}

1 Honda, S., Ito, M., Seki, H., and Jinbo, Y.: 'A disk monopole antenna with 1:8 impedance bandwidth and omnidirectional radiation pattern'. ISAP'92 Sapporo, Japan 1992, pp. 1145-1148

2 Ammann, M.J.: 'Square planar monopole antennas'. IEE Conf. Antennas and Propagation, York, 1999, pp. 37-40

3 Ammann, M.J., and Chen, Z.N.: 'A wideband shorted planar monopole with bevel', IEEE Trans. Antennas Propag., 2003, 51, (4), pp. 901-903
4 Ammann, M.J., and Chen, Z.N.: 'An asymmetrical feed arrangement for improved impedance bandwidth of planar monopole antennas', Microw. Opt. Technol. Lett., 2004, 40, (2), pp. 156-158

5 Song, C.T.P., Hall, P.S., and Ghafouri-Shiraz, H.: 'Multiband multiple ring monopole antennas', IEEE Trans. Antennas Propag., 2003, 51, (4), pp. 722-729

6 Liang, J., Chiau, C., Chen, X., and Parini, C.G.: 'Printed circular disc monopole antenna for ultra wideband applications', Electron. Lett., 2004, 40, (20), pp. 1246-1248

7 John, M., and Ammann, M.J.: 'Optimisation of impedance bandwidth for the printed rectangular monopole antenna', Microw. Opt. Technol. Lett., 2005, 47, (2), pp. 153-154

8 Folayan, O., and Langley, R.J.: 'Compact electromagnetic bandgap antennas', LAPC, 2006, pp. 293-296

9 Liang, J., Chiau, C.C., Chen, X., and Parini, C.G.: 'Study of a printed circular disc monopole antenna for UWB systems', IEEE Trans. Antennas Propag., 2005, 53, (11), pp. 3500-3504

10 Antonino-Daviu, E., Cabedo-Fabrés, M., Ferrando-Bataller, M., and Valero-Nogueira, A.: 'Wideband double-fed planar monopole antennas', Electron. Lett., 2003, 39, (23), pp. 1635-1636

11 Arkko, A.T.: 'Effect of ground-plane size on the free-space performance of a mobile handset PIFA antenna'. IEE Int. Conf. Antennas and Propagation (ICAP), 2003, vol. 1, pp. 316-319

12 Ammann, M.J., and John, M.: 'Optimum design of the printed strip monopole', IEEE Antennas Propag. Mag., 2005, 47, (6), pp. $59-61$

13 Zhang, C., and Fathy, A.E.: 'Development of an ultra-wideband elliptical disc planar monopole antenna with improved omni-directional performance using a modified ground'. IEEE Int. Antennas and Propagation Symp. Dig., 2006, pp. 1689-1692

14 Jan, J.Y., Kao, J.C., Cheng, Y.T., Chen, W.S., and Chen, H.M. 'CPW-fed wideband printed planar monopole antenna for ultra-wideband operation'. IEEE Int. Antennas and Propagation Symp. Dig., 2006, pp. 1697-1700

15 Wang, C.J., and Hse, D.F.: 'Studies of the microstrip monopole antenna with windowed groundplane', Microw. Opt. Technol. Lett., 2004, 42, (5), pp. 407-411

16 Sze, J.Y., and Wong, K.L.: 'Bandwidth enhancement of a microstrip-line-fed printed wide-slot antenna', IEEE Trans. Antennas Propag., 2001, 49, (7), pp. 1020-1022

17 Qing, X., Chia, M.Y.W., and Wu, X.: 'Wide slot antenna for UWB applications'. IEEE Int. Antennas and Propagation Symp. Dig., Boston, 2001, pp. 1834-1837

18 Li, P., Liang, J., and Chen, X.: 'Study of printed elliptical/circular slot antennas for ultrawideband applications', IEEE Trans. Antennas Propag., 2006, 54, (6), pp. 1670-1675

19 Lui, W.J., Cheng, C.H., and Zhu, H.B.: 'Compact frequency notched UWB fractal printed slot antenna', IEEE Microw. Wirel. Compon. Lett., 2006, 16, (4), pp. 24-226

20 Liu, Y.F., Lau, K.L., Que, Q., and Chan, C.H.: 'Experimental studies of printed wide-slot antenna for wide-band applications', IEEE Antennas Wirel. Propag. Lett., 2004, 3, pp. $273-275$ 